\title{
RECONSTRUCCIÓN FONOLÓGICA DEL PIDGIN AFROPORTUGUÉS AMERICANO: LAS VOCALES
}

\author{
Mario Portilla
}

\begin{abstract}
RESUMEN
En el presente artículo presenta la reconstrucción de las protovocales de un pidgin afroportugués utilizado en América durante el siglo XVII mediante la aplicación del Método Comparativo.

Palabras clave: Lenguas criollas, pidgin portugués, reconstrucción fonológica, saramaca, papiamento, palenquero.
\end{abstract}

\begin{abstract}
This article provides the proto-vowel reconstruction of an Afro-Portuguese pidgin spoken in the Americas in the XVII Century according to the principles of the Historical Comparative Method. Key words: Creole languages, Portuguese pidgin, phonological reconstruction, saramaccan, papiamentu, palenquero.
\end{abstract}

\section{Introducción}

Los primeros exploradores y comerciantes portugueses habrían utilizado a propósito una especie de portugués simplificado en las primeras exploraciones de África, las cuales se iniciaron en 1471 (Naro 1978, Clements 1992). Este pidgin primitivo fue usado extensamente en la interacción con la población nativa y entre los esclavos en los territorios de dominio portugués de África Occidental. Todos los criollos de base portuguesa utilizados en África Occidental provienen, en última instancia, de este protopidgin. Estos son el caboverdiano, el criollo de Guinea-Bissau, el saotomense, el angolar, el principense y el anobonés (cf. Holm 1989 y Smith 1995).

Dr. Mario Portilla. Profesor Catedrático de la Escuela de Filología, Lingüística y Literatura, Universidad de Costa Rica. San Pedro, San José, Costa Rica.

Correo electrónico: marioportilla2000@yahoo.com

Recepción: 11- 12- 2008

Aceptación: 4- 2- 2009 
Dado que los portugueses poseyeron el monopolio de la trata de esclavos desde África hacia América hasta finales del siglo XVI, se supone con bastante certeza que los esclavos utilizarían un pidgin de base portuguesa como medio de comunicación en las plantaciones de las colonias americanas. A partir del siglo XVII otras potencias coloniales europeas rompen el monopolio portugués de la trata de esclavos hacia América. Sin embargo, estas naciones continúan utilizando la infraestructura de los fuertes para la trata de esclavos arrebatada a los portugueses. En estos fuertes se habría seguido utilizando el mismo pidgin portugués, el cual igualmente sería llevado a América por los esclavos africanos (Perl 1989b).

El saramaca (Surinam), el papiamento (Antillas Holandesas) y el palenquero (Colombia) son las lenguas criollas americanas que provienen de este protopidgin afroportugués ${ }^{1}$. Ciertamente, aún es debatido el origen, e incluso la filiación, de estos criollos ${ }^{2}$. Sin embargo, Portilla (2008) ha mostrado que estas variedades poseen un vocabulario común (unos 27 rubros), el cual presenta particularidades que solo comparten estas lenguas y que no aparecen ni en el portugués estándar ni en el español. Este hecho constituye un indicio lingüístico muy fuerte del origen compartido de estos criollos.

De acuerdo con datos históricos y demográficos, se supone que el saramaca habría sido criollizado alrededor de 1700 (Bartens 1995 y Bakker et al. 1995) ${ }^{3}$, mientras que el papiamento se criollizaría entre 1650 y 1700 (Bartens 1995 y Kouwenberg \& Muysken 1995) . No se tiene una fecha cierta de cuando pudo haber sido criollizado el palenquero. Sin embargo, se supone que el Palenque de San Basilio ya habría sido establecido en la segunda mitad del siglo XVII por esclavos escapados de las plantaciones de los alrededores de Cartagena de Indias (Schwegler 1998, Patiño 2002).

La información histórica indica, pues, que estos tres criollos pueden perfectamente provenir de una misma variedad de pidgin portugués utilizada en América entre mediados del siglo XVII y principios del siglo XVIII.

Finalmente, se debe mencionar que los criollos de base portuguesa y española de Asia y el Pacífico ${ }^{5}$ habrían tenido su origen en un pidgin portugués distinto del que se usaba en el Atlántico (cf. Stolz 1987, Bartens 1995, Lipski 2002, Clements 1999 y 2000).

\section{Propósito de la investigación}

Portilla (2008) ha logrado reconstruir una lista de 60 rubros del protopidgin afroportugués americano, a partir de los cognados compartidos por dos o tres de los criollos ibéricos mencionados. El objetivo de la investigación es establecer una sistematización de las principales regularidades del cambio lingüístico que permitan la reconstrucción fonológica del protopidgin afroportugués americano, mediante la aplicación del Método Comparativo a los cognados del saramaca, el papiamento y el palenquero. En el presente trabajo se ofrecen los resultados de la reconstrucción de los protosegmentos vocálicos simples, los diptongos y las vocales epentéticas.

Aparte de los cognados ya presentados en Portilla 2008, se han tomado en cuenta otros cognados establecidos posteriormente con base en las listas de vocabulario disponibles de las tres lenguas. Los materiales para la comparación han sido tomados de las siguientes fuentes: Para el saramaca, los datos son de Huttar (1972), el Saramaccan - English Dictionary del SIL (Summer Institute of Linguistics) y Taylor (1977); para el papiamento son de Maurer (1998b), Maduro (1987), el Papiamento-English/English-Papiamento lexicon y el Amaro's 
papiamentu project; y para el palenquero son de Maduro (1987), Cásseres (2005), Megenny (1986) y Friedemann \& Patiño (1983).

\section{Los sistemas fonológicos de las variedades comparadas}

\subsection{El saramaca}

El sistema vocálico de este criollo ${ }^{6}$ consta de siete vocales orales, que se caracterizan con los rasgos distintivos [+/- anterior], [+/- posterior], [+/- alto], [+/- bajo] y [+/- tenso] (cuadro 1.1). También, en esta lengua, existe el contraste entre vocales cortas y largas $[+/-$ largo]. Sin embargo, dado que cada mora de las vocales largas puede presentar un tonema distinto, se han preferido aquí interpretar las vocales largas como una secuencia de dos vocales iguales.

\section{Cuadro 1.1.}

Vocales del saramaca

$\begin{array}{lccc} & \text { [tanterior] } & \text { [+posterior] } \\ \text { [+alto] } & \mathrm{i} & \mathrm{u} \\ \text { [-alto [+tenso] } & \mathrm{e} & & \mathrm{o} \\ \text { [-bajo] [-tenso] } & \varepsilon & \mathrm{a} & 0 \\ \text { [+bajo] } & & \end{array}$

El sistema consonántico consta de 27 segmentos: seis oclusivas simples, dos africadas, dos labiovelares, cuatro fricativas, cuatro oclusivas prenasalizadas, tres nasales, una lateral y tres aproximantes (cuadro 1.2).

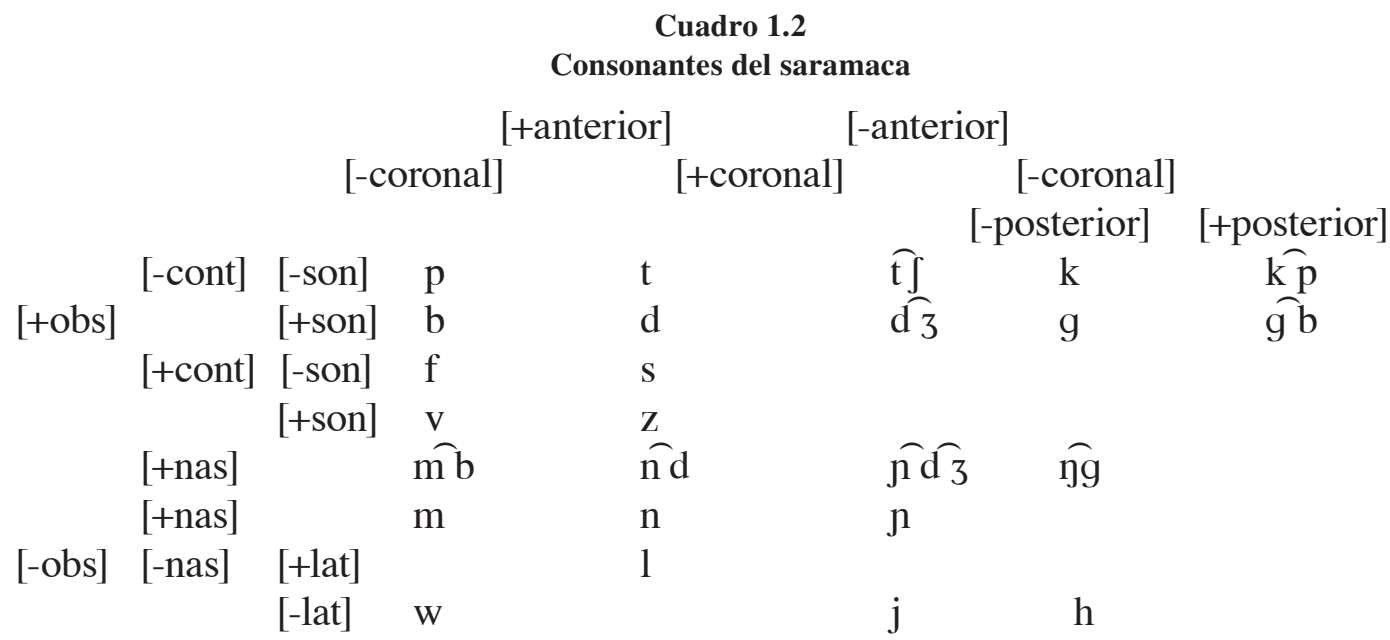

El saramaca presenta además dos tonos de nivel con carácter fonémico: uno alto (marcado aquí con una tilde) y uno bajo (no marcado gráficamente), los cuales ocurren sin restricción de aparición en cualquier sílaba de la palabra.

$\begin{array}{ll}\text { tú } & \text { dos } \\ \text { tu } & \text { también } \\ \text { maaká } & \text { notar }\end{array}$


$\begin{array}{ll}\text { maáka } & \text { presagio } \\ \text { maká } & \text { espina }\end{array}$

\subsection{El papiamento}

El papiamento ${ }^{7}$ presenta un sistema de nueve fonemas vocálicos, los cuales se distinguen por los siguientes rasgos distintivos: [+/- anterior], [+/- posterior], [+/- alto], [+/- bajo], [+/tenso] y [+/- redondeado] (cuadro 1.3). Maurer (1998b) menciona que los fonemas vocálicos /y, $\phi /$ se utilizan solamente en préstamos holandeses y en un registro de habla culta.

\begin{tabular}{|c|c|c|}
\hline & $\begin{array}{r}\mathrm{Cu} \\
\text { Vocales c }\end{array}$ & \\
\hline & $\begin{array}{c}{[\text { +anterior }]} \\
{[\text {-red] }[+ \text { red] }}\end{array}$ & [+posterior $]$ \\
\hline [+alto] & $\mathrm{y}$ & $\mathrm{u}$ \\
\hline [-alto [+tenso] & e & $\mathrm{o}$ \\
\hline [-bajo] [-tenso] & $\varepsilon$ & o \\
\hline [+bajo] & & \\
\hline
\end{tabular}

Esta lengua presenta 23 consonantes: seis oclusivas simples, dos africadas, siete fricativas, tres nasales, una lateral, una vibrante múltiple y tres aproximantes (cuadro 1.4).

Cuadro 1.4

Consonantes del papiamento

\begin{tabular}{|c|c|c|c|c|c|c|}
\hline \multirow{3}{*}{\multicolumn{2}{|c|}{$[\mathrm{C}$ [ ] }} & \multicolumn{3}{|c|}{ [+anterior] } & \multicolumn{2}{|c|}{ [-anterior] } \\
\hline & & & oronal] & [+coronal] & & [-coronal] \\
\hline & & [-son] & $\mathrm{p}$ & $\mathrm{t}$ & $\widehat{t} \int$ & $\mathrm{k}$ \\
\hline \multirow[t]{4}{*}{ [+obs] } & & [+son] & $\mathrm{b}$ & d & $d \sqrt{3}$ & g \\
\hline & {$[+$ cont $]$} & [-son] & $\mathrm{f}$ & $\mathrm{s}$ & $\int$ & $\mathrm{x}$ \\
\hline & & {$[+$ son $]$} & $\mathrm{v}$ & $\mathrm{z}$ & 3 & \\
\hline & [+nas] & & $\mathrm{m}$ & $\mathrm{n}$ & $\mathrm{n}$ & \\
\hline \multirow[t]{2}{*}{ [-obs] } & [-nas] & [+lat] & & 1 & & \\
\hline & & [-lat] & w & $\mathrm{r}$ & $\mathrm{j}$ & $\mathrm{h}$ \\
\hline
\end{tabular}

Para establecer una comparación más homogénea entre las variedades, en este trabajo, las paravocales [ $\mathrm{w}, \mathrm{j}$ ] son consideradas manifestaciones fonéticas de las vocales / u, i / respectivamente, cuando aparecen formando diptongo con otras vocales y en posición no inicial de sílaba (cf. Maurer 1998: 148). Pero, en posición inicial de sílaba. se representan como fonemas autónomos / w, j/.

En cuanto a los suprasegmentales, esta lengua presenta, por un lado, un acento de intensidad de carácter contrastivo por palabra (representado aquí por una comilla antes de la sílaba acentuada, tal como se recomienda en el Alfabeto Fonético Internacional). En la mayor parte de los casos, la colocación del acento ocurre en la penúltima sílaba cuando la palabra termina en vocal o en -er, -el y -en (en cuyo caso o bien la vocal tiende a debilitarse o bien estos sonidos son sustituidos por la vocal -u) y en la última sílaba cuando la palabra termina en consonante. La mayor parte de las excepciones a estas reglas la constituyen verbos de tres 
o cuatro sílabas terminados en vocal, los cuales llevan el acento en la última sílaba. También, hay un número considerable de sustantivos (y participios) de dos sílabas terminados en vocal que llevan el acento en la última sílaba.

$\begin{array}{ll}\text { ku'minda } & \text { comida } \\ \text { kumin'da } & \text { saludar } \\ \text { 'mata } & \text { matar } \\ \text { ma'ta } & \text { matado } \\ \text { 'homber } & \text { hombre } \\ \text { mu'he } & \text { mujer }\end{array}$

Además, esta lengua presenta dos tonemas: un tono alto (representado aquí con una tilde) y un tono bajo (sin representación gráfica). En muchas ocasiones el tono alto aparece en la vocal de la sílaba acentuada, pero en el caso de los verbos, y de algunos pocos sustantivos, pronombres y adverbios, el tono alto recae sobre la última vocal inacentuada.

$\begin{array}{ll}\text { 'máta } & \text { mata, planta } \\ \text { 'matá } & \text { matar } \\ \text { ma'tá } & \text { matado } \\ \text { 'pára } & \text { pájaro } \\ \text { 'pará } & \text { parar } \\ \text { pa'rá } & \text { parado } \\ \text { 'mut Já } & \text { muchacho } \\ \text { 'bosó } & \text { ustedes } \\ \text { 'akí } & \text { aquí }\end{array}$

A diferencia del saramaca, el papiamento presenta la restricción de la aparición de un solo tono alto por palabra polisílaba, lo cual indica que esta lengua es del tipo llamado de acento tonal.

\subsection{El palenquero}

Los diversos autores ${ }^{8}$ coinciden en que el palenquero presenta un sistema fonológico muy cercano al descrito para el llamado español del Caribe. El sistema vocálico está compuesto por cinco segmentos, los cuales se diferencian por los rasgos distitivos: [+/- anterior], [+/posterior], [+/- alto] y [+/- bajo] (cuadro 1.5).

\section{Cuadro 1.5.}

Vocales del palenquero

[+alto]

[-alto, -bajo]

[+bajo] [+posterior]

[+anterior]

i

$\mathrm{e}$

$\mathrm{u}$

o

El sistema consonántico está compuesto por 17 segmentos: seis oclusivas simples, dos africadas, dos fricativas, tres nasales, una lateral, una vibrante múltiple, una vibrante simple y una aproximante (cuadro 1.6). 


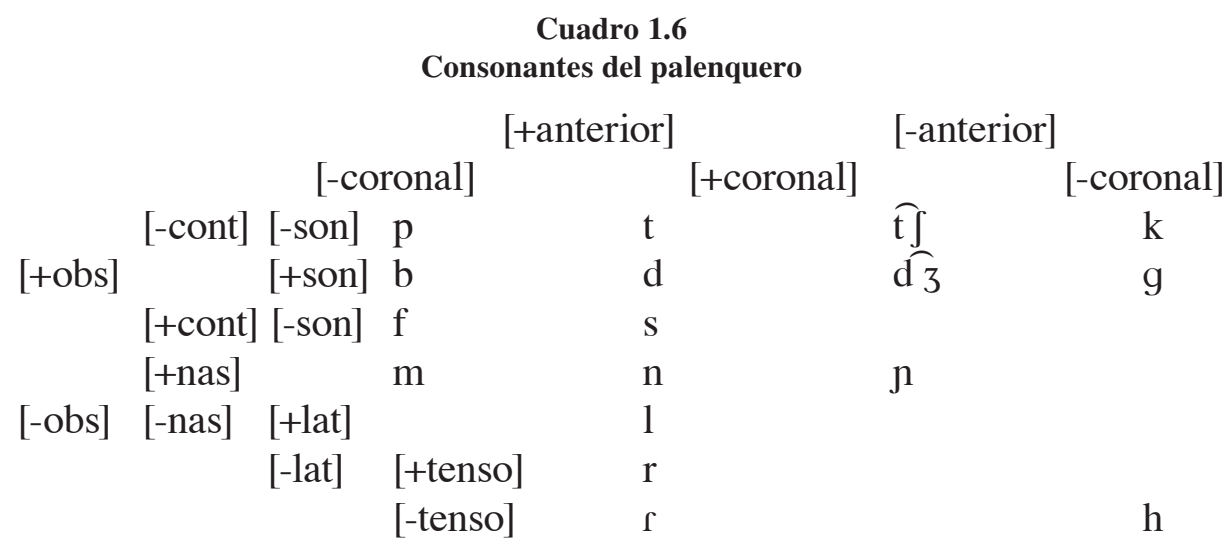

Es importante señalar dos aspectos en relación con las consonantes en palenquero ${ }^{9}$. En primer lugar, todos los autores mencionan la existencia de consonantes prenasalizadas, especialmente de una serie de oclusivas sonoras prenasalizadas $[\widehat{\mathrm{m}} \mathrm{b}, \widehat{\mathrm{nd}}, \widehat{\mathrm{jg}}]^{10}$. Estas aparecen en posición inicial de palabra (inicial absoluta y después de vocal), pero alternando más o menos libremente con las oclusivas sonoras correspondientes. Para fines comparativos, se ha optado en este trabajo por representar fonológicamente estas oclusivas prenasalizadas como la secuencia de una nasal y una oclusiva sonora /mb, nd, ng/:

$\begin{array}{ll}\text { mbósa } & \text { bolsa } \\ \text { mbosá } & \text { bozal } \\ \text { ndoló } & \text { dolor } \\ \text { ndá } & \text { dar } \\ \text { ngánde } & \text { grande } \\ \text { ngú ba } & \text { maní }\end{array}$

Por otro lado, es muy probable que la consonante vibrante múltiple / $\mathrm{r} /$ haya sido introducida en palenquero recientemente por influencia del superestrato español, ya que este segmento suele ser reemplazado por el fonema lateral / 1 / en gran parte de los étimos de vocabulario más básico.

$\begin{array}{ll}\text { pé lo } & \text { perro } \\ \text { balé } & \text { barrer } \\ \text { kulé } & \text { correr } \\ \text { ngalá } & \text { agarrar }\end{array}$

En cuanto a los suprasegmentales, Bickerton y Escalante 1968 sostienen que esta lengua presenta un acento melódico más que de intensidad. Aunque Friedemann y Patiño 1983 señalan que el palenquero tiene un acento espiratorio que no difiere notablemente del español, la misma breve caracterización que estos autores ofrecen de la entonación de esta lengua, permite suponer que el palenquero sea una lengua de acento tonal. Esto significa que, como en el caso del papiamento, un tono alto (o un acento de altura) tiene una aparición restringida a una sílaba por palabra polisílaba. Por ello, y para facilitar la comparación de los cognados, se ha decidido representar aquí el acento por medio de una tilde (que es el símbolo que corresponde a un tono alto, según lo recomendado en el Alfabeto Fonético Internacional). 


\section{Las protovocales}

Para el pidgin afroportugués americano, es posible reconstruir un sistema de cinco vocales orales, el cual puede ser definido con los rasgos distintivos [+/- anterior], [+/posterior], [+/- alto] y [+/- bajo] y (cuadro 2.1).

Cuadro 2.1.

Protovocales del pidgin afroportugués americano

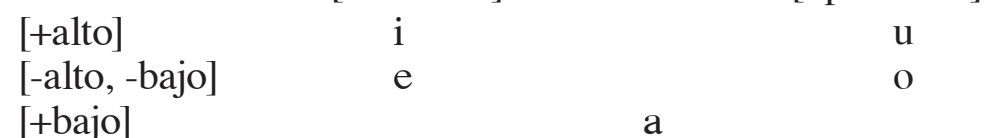

Las protovocales presentan las siguientes correspondencias en las variedades comparadas:

3.1. $* \mathbf{i}$

saramaca papiamento palenquero

a. $/ \mathrm{i} /$

/ i / / i /

pidî 'pidí pirí

akí 'akí akí

baí ka ${ }^{11}$

ba'rỉ ka

baríka

*pidí

pedir

duumíl 12

'drumí

drumí,

*barỉka

aquí

kaí

ndrumí

lỉba 'rỉba

kaí

*drumí

estómago, barriga

papiá

'papiá

ríba

*kaí

*ríba

dormir

papia $^{13}$

*papiá

caer

sobre, encima de

hablar, charlar

b.

\begin{tabular}{|c|c|c|c|c|}
\hline / i / & / i / & / e / & & \\
\hline & $\begin{array}{l}\text { 'sá bi, } \\
\text { 'sá }\end{array}$ & sábe & *sábi & saber \\
\hline gaándi1 ${ }^{14}$ & 'grándi & $\begin{array}{l}\text { ngánde, } \\
\text { qlánde }\end{array}$ & *grándi & grande \\
\hline
\end{tabular}

El haz de correspondencias (b) está restringido a la sílaba inacentuada (o con vocal de tono bajo) en posición final de palabra. Es conocido que, en las lenguas iberorromances, solamente pueden aparecer tres vocales en sílaba inacentuada final de palabras: / i, u, a / o /e, o, a / (cf. Portilla 1987). Dado que, en dicha posición, en español aparecen las vocales / e, o, a /, no es extraño que las formas actuales del palenquero hayan sido modificadas según el patrón fonológico del español.

En palenquero, aparece un término, claramente de origen portugués, que presenta la alternancia entre las vocales / e $\sim \mathrm{i} /$ :

éle éli < port. eli 'él' cf. esp. él

También, esta alternancia ocurre en otros rubros cuyo origen puede ser tanto portugués o español:

éste $\sim$ ésti < port. o esp. este 'este'

ónsi < port. onze o esp. once 'once' 
ónde < port. onde o esp. onde 15 'donde'

En palabras de claro origen español, sin embargo, predomina la vocal / e /:

lét $\int \mathrm{e}<\mathrm{esp}$. leche

cf. port. leite

ómbe, ómbre < esp. hombre

cf. port. homen

síempre < esp. siempre

cf. port. sempre

A continuación se presentan otros rubros del saramaca de origen claramente portugués que muestran la aparición de la vocal / i / en esta posición:

pénti < port. pente 'peine'

kéndi < port. quente 'caliente'

wómi < port. homen 'hombre'

3.2. $* \mathrm{u}$

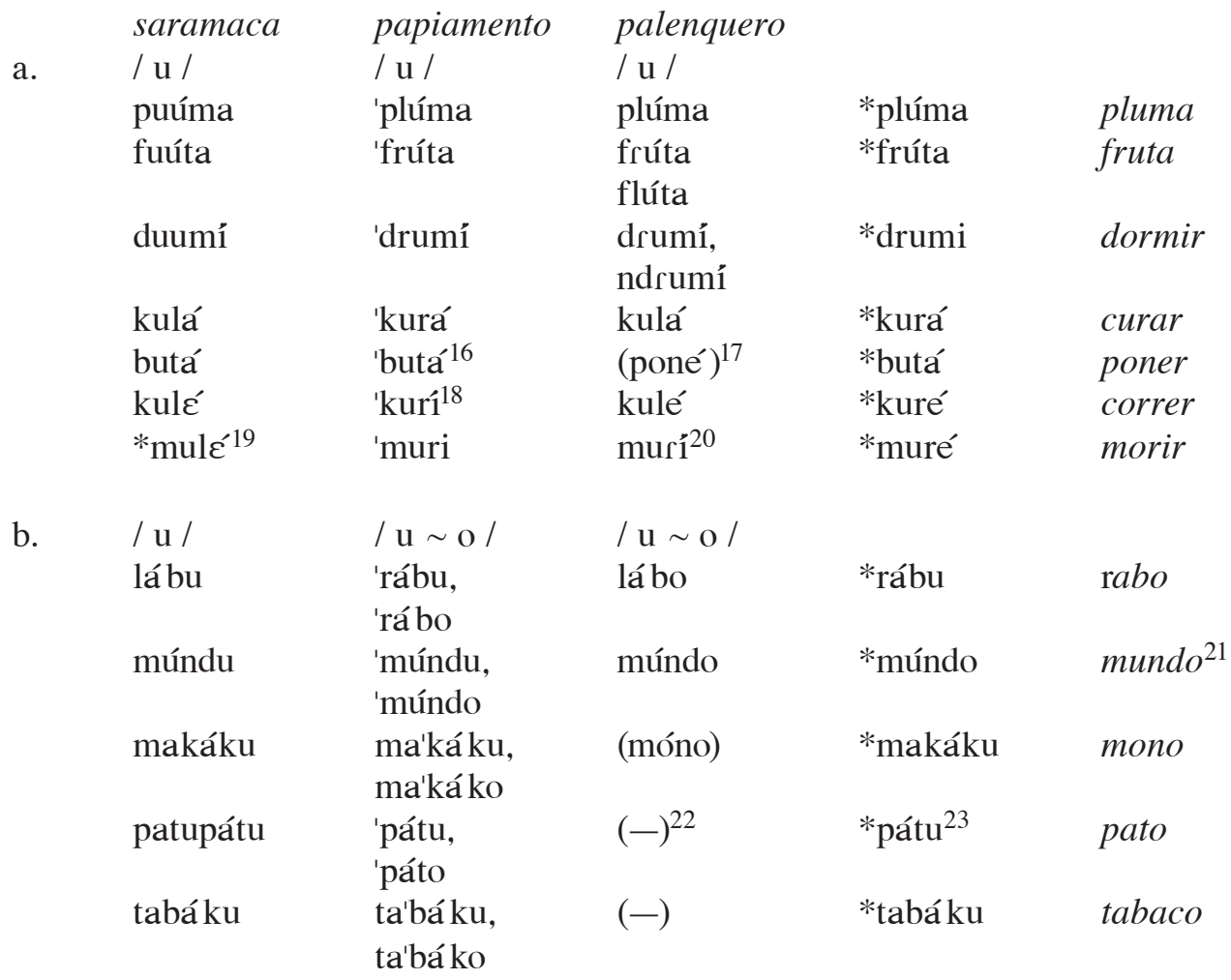

Como se mencionado antes, en posición de sílaba final de palabra inacentuada, en las lenguas iberorromances, existe una alternancia entre los fonemas / u o /. En papiamento, esta alternancia está muy extendida tanto en étimos de origen portugués como español.

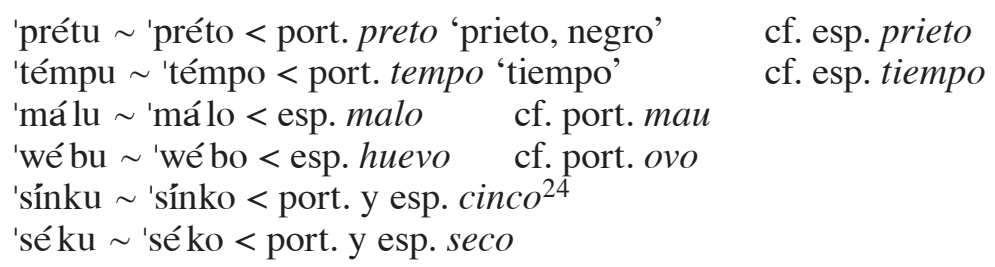


En palenquero, también ocurre la alternancia entre los fonemas / u o /. Sin embargo, esta aparece solamente en unos pocos rubros.

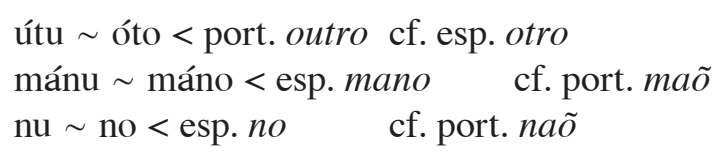

$\begin{array}{lllll}\text { c. } \quad / \mathrm{o} / & / \mathrm{u} \sim \mathrm{o} / & / \mathrm{u} \sim \mathrm{o} / & & \\ \text { óto } & \text { 'oto } & \text { útú, óto } & \text { *ótu } & \text { otro } \\ \text { lío } & \text { 'ríu } & \text { (río) } & \text { *ríu } & \text { río } \\ \text { línzo } & \text { 'lízu } & (-) & \text { *lízu } & \text { liso }\end{array}$

En saramaca, el cambio de *u > o ocurre también en la posición de sílaba inacentuada (o con una vocal de tono bajo) final de palabra de la protolengua.

Aunque no se han hallado más cognados seguros de este haz de correspondencias entre el saramaca y el papiamento, es posible encontrar algunos pocos ejemplos más en el saramaca que ilustran este cambio.

tío < port. tio "tío materno"25

límbo, límpo < port. limpo 'limpio'

wó jo < port. olho 'ojo'

pió jo < port. piolho 'piojo'

óbo, wóbo < port. ovo 'huevo'

De acuerdo con los ejemplos anteriores, el cambio *u $>$ o parece estar favorecido por el hecho de que el segmento que precede a la vocal *u sea sonoro. Riemer 1779 recoge una mayor cantidad de rubros con la vocal 'o' en este contexto del que existe en la actualidad.

$\begin{array}{llll}\text { 1779 } & \text { forma actual } & & \\ \text { 'labo' } & \text { lábu } & \text { < port. rabo } & \text { 'rabo' } \\ \text { 'lòlo' } & \text { lólu } & \text { < port. rolo } & \text { 'rollo' } \\ \text { 'pikkado' } & \text { pikádu } & \text { < port. pecado } & \text { 'pecado' } \\ \text { 'co' } & \text { ku } & \text { < port. com } & \text { 'con, y' } \\ \text { 'limbo' } & \text { límbo, limpo } & \text { < port. limpo } & \text { 'limpio' } \\ \text { 'lío' } & \text { lío } & \text { < port. rio } & \text { 'río' } \\ \text { 'kàttibo' } & \text { katíbo } & \text { < port. cativo 'esclavitud'26 }\end{array}$

Por otro lado, los rubros que aparecen en Riemer 1779 con la vocal 'u' en dicha posición siempre son idénticos a formas actuales que tienen una vocal / $\mathrm{u} /$ final.

$\begin{array}{lll}\text { I779 } & \text { forma actual } & \\ \text { 'makàku' } & \text { makáku } & \text { < port. macaco 'mono' } \\ \text { 'matu' } & \text { mátu } & \text { < port. mato 'bosque' } \\ \text { 'bitju' } & \text { bítfu } & \text { < port. bicho 'gusano'27 } \\ \text { 'mundu' } & \text { múndu } & \text { < port. mundo 'universo'28 } \\ \text { 'feru' } & \text { félu } & \text { < port. ferro 'metal'29 } \\ \text { 'blaku' } & \text { baáku } & \text { < port. buraco 'agujero, hoyo' }\end{array}$

Esta situación del saramaca es muy afín con la tendencia general de las lenguas iberorromances, con una inestabilidad entre las vocales / u $\sim \mathrm{o} /$ en posición de sílaba inacentuada final de palabra. 
Además, en las tres variedades, la aparición de las vocales finales / u o / también parece estar propiciada por la presencia de una vocal similar en la sílaba anterior. Este fenómeno se ilustra muy bien en el caso del rubro otro:

óto, wóto 'óto útu, óto otro

\begin{tabular}{|c|c|c|c|c|}
\hline $\begin{array}{l}\text { / u } \sim \mathrm{o} / \\
\text { bít } \int \mathrm{u}\end{array}$ & $\begin{array}{l}\text { / i / } \\
\text { 'bít Ji }\end{array}$ & $\begin{array}{l}/-/ \\
\text { (ngusáno) }\end{array}$ & *bit $\int u$ & gusano \\
\hline súndzu & 'su $\int i$ & (súsio) & *súdzu & sucio \\
\hline $\begin{array}{l}\text { límbo, } \\
\text { límpo }\end{array}$ & 'lỉmpi & $\begin{array}{l}\text { (límpio, } \\
\text { lỉmpiu) }\end{array}$ & *límpu & limpio \\
\hline
\end{tabular}

En papiamento, el cambio de $* u>$ i sucede solamente en la posición de sílaba inacentuada (o con una vocal de tono bajo) final de palabra de la protolengua. Este cambio vocálico parece estar determinado, por un lado, por una consonante prepalatal precedente / t $\int$, d3 / (rubros gusano y sucio). Por otro lado, este cambio puede estar favorecido también por la vocal / i / de la sílaba anterior (rubros gusano y limpio).

A continuación se presentan otros ejemplos que ilustran en este cambio vocálico en papiamento.

$$
\begin{aligned}
& \text { o'ló } \int \mathrm{i}<\text { port. relogio 'reloj' } \\
& \text { Ji'ní } \int \mathrm{i}<\mathrm{esp} \text {. ceniza 'ceniza' } \\
& \text { 'ké } \int \mathrm{i}<\mathrm{esp} \text {. queso 'queso' } \\
& \text { bu'rát } \int \mathrm{i}<\mathrm{esp} \text {. borracho 'borracho' } \\
& \text { 'drét } \int \mathrm{i}<\mathrm{esp} \text {. derecha 'a la derecha' }
\end{aligned}
$$

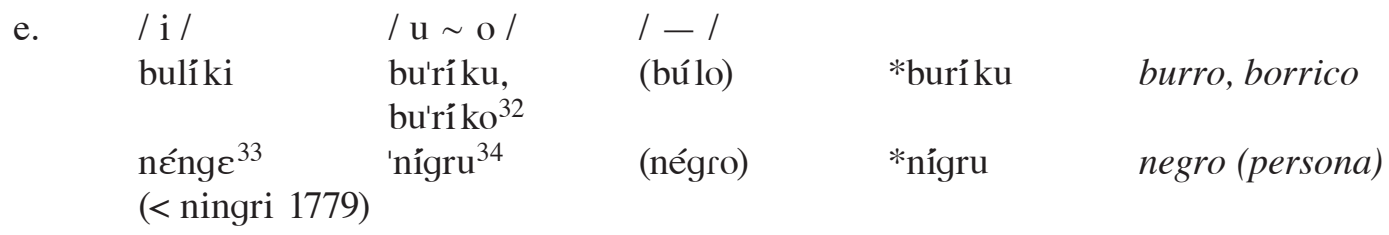

En saramaca, el cambio de $* \mathrm{u}>\mathrm{i}$ parece estar condicionado por la presencia de la vocal / i / de la sílaba anterior. Otro ejemplos que ilustran este cambio en saramaca son los siguientes:

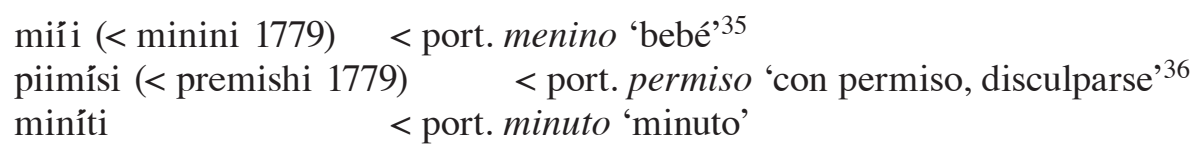

Sin embargo, esta regla presenta excepciones:

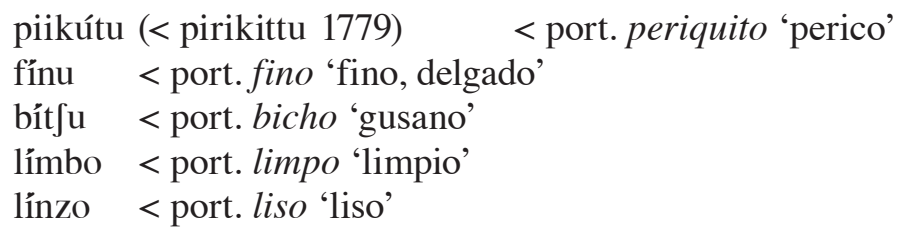

El cambio de $* \mathrm{u}>\mathrm{i}$ aparece en la palabra pikníni $<*$ pikinínu (port. pequenino) niño, la cual se encuentra en varias lenguas criollas de base inglesa del Atlántico ${ }^{37}$. Esta forma ha sido considerada un resabio del pidgin afroportugués usado en el Atlántico (Cassidy 1971). 
3.3. * $\mathrm{e}$

$\begin{array}{lllll}\text { saramaca } & \text { papiamento } & \text { palenquero } & & \\ \text { a. } & \text { / e / } / & \text { / e / } & & \\ \text { bebé } & \text { 'bebé } & \text { bebé } & \text { *bebé } & \text { beber } \\ \text { dendá38 } & \text { 'drentá } & \text { lendrá } & \text { *dentrá } & \text { entrar } \\ \text { feegá, } & \text { 'fregá } & \text { fregá } & \text { *fregá } & \text { fregar } \\ \text { feigá } & & & & \\ \text { té } & \text { 'té } & \text { (áta, áhta) } & \text { *té } & \text { hasta } \\ \text { (a) } & \text { 'éle } & \text { éli } & \text { *éli } & \text { él } \\ \text { téla } & \text { 'téra } & \text { (tiéla) } & \text { *téra } & \text { tierra }\end{array}$

$\begin{array}{lllll}\text { b. } / \varepsilon / & / \mathrm{e} / & / \mathrm{e} / & & \\ \text { kəmé } & \text { 'komé } & \begin{array}{l}\text { kumé, } \\ \text { komé }\end{array} & \text { *komé } & \text { comer } \\ \text { sendét } & \text { 'sendé } & (-) & \text { *sendé } & \text { encender }\end{array}$

En saramaca, el cambio $*$ e $>\varepsilon$ ocurre en posición final de palabra, cuando la vocal está precedida por las protovocales medias $*_{\mathrm{e}}$, $*_{\mathrm{o}} \mathrm{y} *_{\mathrm{u}}$ y por una protoconsonante sonora. Otros ejemplos de la aplicación de esta regla en saramaca son los siguientes:

\begin{tabular}{|c|c|c|}
\hline mujéc (1779 mujề & *mujér ${ }^{41}$ & $<$ port. mulher 'mujer' \\
\hline kujéc (1779 kujéri) & *kujér ${ }^{42}$ & $<$ port. colher 'cuchara' \\
\hline mesíte & *méstre ${ }^{43}$ & $<$ port. mestre 'maestro' \\
\hline tendé & *tendé & $<$ port. tender 'extender, tender la mano' \\
\hline kulé & *kuré & < port. correr 'correr' \\
\hline tánapé & *táempé44 & $<$ port. estar em pe 'estar de pie' \\
\hline
\end{tabular}

Esta regla de apertura vocálica en posición final de palabra es aplicada también a palabras de origen inglés ${ }^{45}$ y de otras lenguas.

\begin{tabular}{|c|c|c|}
\hline pé́ & *plé: & < ing. play 'jugar' \\
\hline kónde & *kíntri ${ }^{46}$ & $<$ ing. country 'pueblo' \\
\hline suméc & *smél & < ing. smell 'oler' \\
\hline $\mathrm{d} \varepsilon ́ \mathrm{~d} \varepsilon$ & *déd & $<$ ing. dead 'morir, muerto'47 \\
\hline fénse & & $<$ hol. venster 'ventana' \\
\hline $\operatorname{l\varepsilon g} \varepsilon \mathrm{d} \varepsilon$ & & $<$ orig. desc. 'chisme' \\
\hline vévé & & $<$ orig. desc. 'fuego' \\
\hline
\end{tabular}

Por otro lado, el cambio $*$ e $>\varepsilon$ ocurre también por una regla de asimilación, la cual produce la apertura de las vocales medias / e, o / de las sílabas precedentes. Esta regla explica el cambio producido en las vocales de sílabas no finales que aparecen en las palabras de origen portugués correspondientes a comer, mujer, cuchara, maestro, brillar y tender la mano.

Esta misma regla de asimilación que produce la apertura de las vocales medias parece haber afectado también a la vocal / u /, la cual probablemente se realizaría fonéticamente como [ $v$ ]. Esto explicaría la alternancia ortográfica $\langle\mathrm{o} \sim \mathrm{u}\rangle$ de ciertos rubros que aparecen en Riemer 1779. 


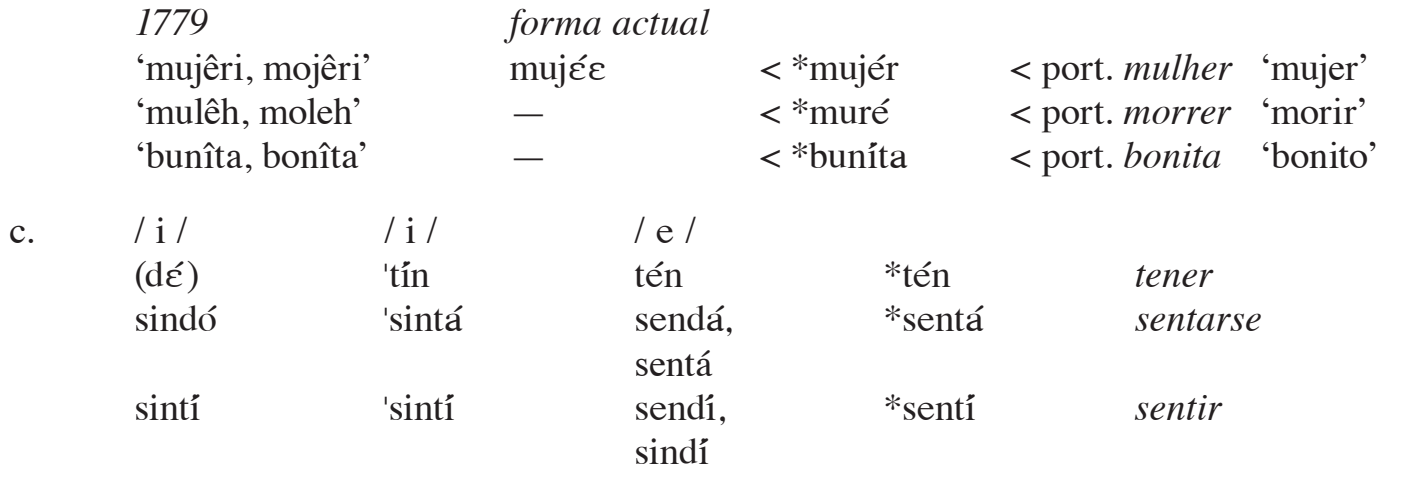

En saramaca y papiamento el cambio *e > i parece estar propiciado por la presencia de la consonante nasal siguiente. Otros ejemplos que ilustran este cambio en saramaca son los siguientes:

$\begin{array}{ll}\text { manỉni }^{48} & \text { < port. maneira 'buenas maneras' } \\ \text { niingá49 } & <\text { port. negar 'negar, rehusar' } \\ \text { 'wintu' (Riemer } 1779)^{50} & <\text { port. ventu 'viento' }\end{array}$

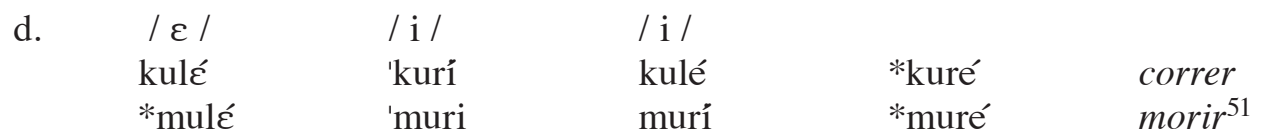

En papiamento y palenquero, el cambio *e > i parece estar propiciado por la presencia de una consonante vibrante precedente. Otro ejemplo de este cambio en papiamento es el siguiente: 'barí < port. varrer 'barrer'

En saramaca, el cambio *e > i ocurre cuando la protoconsonante vibrante estaba precedida por la vocal / a /. balí, baí (1779 'bari, bali') < port. varrer 'barrer'

\section{4. $* 0$}

saramaca papiamento palenquero

$\begin{array}{lllll}\text { a. } & \text { / o / } & \text { / o / } & \text { / o / } & \\ \text { (díki) } & \text { 'kobá } & \text { kobá } & \text { *kobá } & \text { cavar } \\ \text { kómpe } & \text { 'kómpai } & \text { (amígo) } & \text { *kómpai } & \text { amigo } \\ \text { kondá } & \text { 'kontá } & \text { (kuénda) } & \text { *kontá } & \text { contar } \\ \text { lonká } & \text { 'ronká } & (-) & \text { *ronká } & \text { roncar } \\ \text { foló } 52 & \text { 'flór } & \text { fló } & \text { *flór } & \text { flor }\end{array}$

$\begin{array}{lllll}\text { b. } / \mathrm{o} \sim \text { wo } / & / \mathrm{o} / & / \mathrm{u} \sim \mathrm{o} / & & \\ \text { óto, wóto } & \text { 'óto } & \underline{\text { útu, óto }} & \text { *ótu }\end{array}$

En saramaca, el cambio cambio $*_{0}>$ wo está determinado por la posición inicial de palabra. Otros rubros que ilustran este cambio son los siguientes:
wó jo
(1779 oijo)
*óju < port. olho 'ojo'
ómi, wómi
(1779 omi) *ómi < port. homen 'hombre' 


\begin{tabular}{|c|c|c|}
\hline óbo, wóbo & (1779 wobò) & < port. ovo 'huevo' \\
\hline ósu, wósu & (1779 hosso) & $<$ ing. house 'casa' \\
\hline ódi, wódi & (1779 odi, hodi) & ${ }^{*}{ }_{\Lambda} \mathrm{ddI}_{\mathrm{I}}<$ ing. howdy 'hola (saludo)' \\
\hline óli, wóli & & $<$ hol. olie 'gasolina' \\
\hline okó, wokó & & $<$ orig. desc. 'especie de ave' \\
\hline
\end{tabular}

Los términos recogidos por Riemer 1779 indican que el cambio *o $>$ wo no estaba tan generalizado en esa época que como lo está actualmente.

$\begin{array}{llll}\text { c. } / \text { o / } & / \mathrm{o} / & / \mathrm{u} \sim \mathrm{o} / & \\ \text { komé } & \text { 'komé } & \text { kumé, } \\ & \text { komé }\end{array}$ *komé

El cambio *o > 0 ocurre por la asimilación del rasgo de tensión de la vocal de la sílaba siguiente. Al igual que en el caso de la otra vocal media mencionado anteriormente, esta regla de apertura vocálica se aplica también a vocablos de origen inglés y de otras lenguas.

\begin{tabular}{|c|c|c|}
\hline kónde & *kর́ntri & < ing. country 'país' \\
\hline tóngo & *tún & $<$ ing. tongue 'lengua' \\
\hline bวó & *blo: & < ing. blow 'soplar, respirar' \\
\hline móte & & $<$ hol. motor 'motor de bote' \\
\hline potopots & & $<$ orig. desc. 'barro' \\
\hline d3əkotó & & $<$ orig. desc. 'acuclillarse' \\
\hline
\end{tabular}

$\begin{array}{lllll}\text { d. } \quad \text { / u / } & \text { / o / } & /-/ & & \\ \text { búnu } & \text { 'bón } & \text { (búeno) } & \text { *bón } & \text { bueno } \\ \text { suján } & \text { 'sojá } & (-) & \text { *sona } & \text { soñar }\end{array}$

En saramaca, el cambio $*_{\mathrm{o}}>\mathrm{u}$ parece ocurrir cuando la protovocal se encuentra en contacto con una consonante nasal.

Otros ejemplos que ilustran este cambio en saramaca son los siguientes:

3.5. *a

saramaca papiamento palenquero

a.

$\begin{array}{lllll}\text { / a / } & \text { / a / } & \text { / a / } & & \\ \text { kabá } & \text { 'kabá } & \text { kabá } & \text { *kabá } & \text { acabar } \\ \text { dendá } & \text { 'drentá } & \begin{array}{l}\text { lendrá } \\ \text { kulá }\end{array} & \text { *dentrá } & \text { entrar } \\ \text { kandá } & \text { 'kurá } & \text { kulá } & \text { *kurá } & \text { curar } \\ & \text { 'kantá, } & \text { kandá } & \text { *kantá } & \text { cantar } \\ \text { pasá } & \text { kandá } & & & \\ \text { papiá } & \text { 'pasá } & \text { pasá } & \text { *pasá } & \text { pasar } \\ \text { ta } & \text { 'papiá } & \text { papiá } & \text { *papiá } & \text { hablar, conversar } \\ \text { sábi } & \text { 'ta } & \text { ta } & \text { *ta } & \text { aspecto progresivo } 54 \\ \text { akí } & \text { 'sábi, 'sá } & \text { sábe } & \text { *sábi } & \text { saber } \\ \text { húna } & \text { 'akí } & \text { akí } & \text { *akí } & \text { akí } \\ \text { kákísa55 } & \text { 'úna } & (-) & \text { *úna } & \text { garra } \\ & \text { 'káska } & (-) & \text { *káska } & \text { corteza }\end{array}$




\section{Los diptongos}

4.1. *ai

saramaca papiamento palenquero

a. / ai /

/ ai / / ae /

mái

'má i

pái

('pay' 1779)

máe

*má i

madre 56

papakái

'papagá i

páe

*pái

padre 57

(gó)

'bai

(papagád3o)

báe

papagayo

*bái

ir

b. / e /

/ ai /

$1-1$

kómpe

'kómpai

(amígo)

*kómpai

amigo

En saramaca, el cambio *ai > e parece estar restringido a la posición de sílaba inacentuada (o con tono bajo) final de palabra en la protolengua.

4.2. *au

$\begin{array}{cllll} & \text { saramaca } & \text { papiamento } & \text { palenquero } & \\ \text { a. } & \text { / au / } & \text { / ou / } & /-/ & \\ \text { bakajáu } & \text { 'bakijou } & (-) & \text { *bakajáu bacalao }\end{array}$

En papiamento, el cambio también afecta los étimos de origen portugués, español y de otras lenguas.

$\begin{array}{ll}\text { 'salmou } & <\text { port. salmão 'salmón' } \\ \text { 'kakou } & <\text { port. cacau o esp. cacao } \\ \text { 'kousá } & <\text { port. o esp. causar } \\ \text { 'hóula } & <\text { esp. jaula } \\ \text { 'blou } & <\text { hol. blauw 'azul' } \\ \text { 'sous } & <\text { hol. saus 'salsa' }\end{array}$

Otros ejemplos que muestran la aparición de este diptongo en saramaca son los siguientes ${ }^{59}$ :

$\begin{array}{lll}\text { páu } & \text { *páu } & \text { < port. pau 'palo' } \\ \text { máun } & \text { *máun } & <\text { port. mão 'mano' } \\ \text { mamáun } & \text { *mamáun } & <\text { port. mamão 'papaya' }\end{array}$

\section{Algunos cambios por fonemas}

Algunas inconsistencias en las correspondencias sistemáticas descritas en los apartados anteriores deben ser explicadas como la consecuencia de procesos de asimilación o disimilación. Al contar con solamente un ejemplo en cada caso, no es posible saber si estos cambios son regulares o no. 
a. $\quad *$ e $>$ u en vez de $*$ e $>$ i en saramaca:

saramaca papiamento palenquero

/ u / / i / e /

tfumá 'kimá kemá *kemá quemar

En saramaca, el cambio *e $>$ u ocurre probablemente por asimilación a la consonante bilabial siguiente. Riemer 1779 recoge la forma 'tchima', la cual no presenta aún este cambio.

b. $\quad * a>0$ en vez de $* a>a$ en saramaca:

\begin{tabular}{|c|c|c|c|}
\hline saramaca & papiamento & palenquero & \\
\hline $\begin{array}{l}\text { / o / } \\
\text { sindó }\end{array}$ & $\begin{array}{l}\text { / a / } \\
\text { 'sintá }\end{array}$ & $\begin{array}{l}\text { / a / } \\
\text { sendá, } \\
\text { sentá }\end{array}$ & *sentá \\
\hline
\end{tabular}

Riemer 1779 presenta la forma 'sindá'.

c. $\quad * \mathrm{u}>\varnothing$ en vez de $* \mathrm{u}>\mathrm{u}$ en saramaca:

saramaca papiamento palenquero

$\begin{array}{llll}\text { / a / } & / \mathrm{u} / & /-/ & \\ \text { baáku } & \text { 'buráku } & (-) & \text { hueco }\end{array}$

En saramaca, la forma actual se obtiene de la siguiente derivación de la protoforma: *burá $\mathrm{ku}>$ brá $\mathrm{ku}>$ blá $\mathrm{ku}>$ balá $\mathrm{ku}>$ baá ku. La pérdida de la *u se debe presumiblemente a presencia de la consonante labial precedente / b /. Riemer 1779 presenta la forma 'blaku'.

d. $\quad *$ a $>$ i en vez de $*$ a $>$ a en papiamento:

saramaca papiamento palenquero

$\begin{array}{llll}\text { / a / } & \text { / i / } & \text { / } / & \\ \text { bakajáu } & \text { 'bakijou } & (-) & \text { *bakajáu bacalao }\end{array}$

Es probable que el cambio *a $>$ i ocurra por influencia de la aproximante palatal siguiente $/ \mathrm{j} /$.

\section{Vocales paragógicas}

En saramaca, algunas vocales surgen por procesos de paragoge, ya que en esta lengua la estructura silábica preferida es CV. En rubros de origen portugués aparecen los siguientes casos.

a. $\varnothing>\mathrm{i}$

$\begin{array}{llll}\text { saramaca } & \text { papiamento } & \text { palenquero } & \\ \text { alísi } & \text { 'arós } & \text { aló } & \text { *arós arroz } \\ \text { kákísa < kásíka } & \text { 'kaska } & (-) & \text { *káska cáscara }\end{array}$

Otros ejemplos que ilustran este cambio en saramaca son los siguientes:

$\begin{array}{lll}\text { bambúsi } & \text { *bambús } & <\text { port. bambu 'bambú' } \\ \text { adzóisi } & \text { *adzóis } & <\text { port. adeus 'adiós' } \\ \text { siné isi } & \text { *jinés } & <\text { port. chinês 'chino' }\end{array}$


La inclusión de esta vocal ocurre cuando la protoconsonante / s / se halla en posición final absoluta (final de palabra) (v.gr. *arós > alísi) o seguida de una consonante (v.gr. *káska $>$ kásíka). Esta regla se aplica también a los rubros de origen inglés y holandés.

$\begin{array}{ll}\text { gáasi } & <\text { ing. glass 'vaso' } \\ \text { pási } & \text { <ing. path 'sendero' } \\ \text { físi } & <\text { ing. fish 'pez' } \\ \text { sitónu } & \text { <ing. stone 'piedra' } \\ \text { sindé ki } & <\text { ing. snake 'culebra' } \\ \text { matáasi } & <\text { hol. matras 'colchón' } \\ \text { báasi } & <\text { hol. blaas 'vegiga, balón' } \\ \text { tási } & <\text { hol. tas 'bolsa'60 }\end{array}$

b. $\varnothing>\mathrm{u}$

$\begin{array}{lll}\text { saramaca } & \text { papiamento } & \text { palenquero } \\ \text { búnu } & \text { 'bon } & \text { (buéno) }\end{array}$

La inclusión de esta vocal ocurre cuando la palabra termina en la protoconsonante / $\mathrm{n}$ /, cuando está precedida por una vocal simple no anterior ${ }^{61}$. Esta regla se aplica también a los rubros de origen inglés y holandés.

$\begin{array}{ll}\text { pánu } & <\text { ing. pan 'sartén' } \\ \text { babúnu } & <\text { ing. baboon 'babún' } \\ \text { bónu } & <\text { ing. bone 'hueso' } \\ \text { sitónu } & <\text { ing. stone 'piedra' } \\ \text { buúu } 62 & <\text { hol. bloed 'sangre' }\end{array}$

En 1779, esta regla tenía restricciones en su aplicación. Riemer 1779 presenta las formas 'bunn' y 'bunnu' bueno y anota lo siguiente: bunn sagt man, wenn es alleine steht. bunnu aber, wenn es nut einem anderen Wort genau verbunden ist. z.B. di fruta a bunn die Frucht ist gut; hem wan bunnu fruta das ist eine gute Frucht. Además, recoge las formas 'babùn' babún, 'boon' hueso y 'stoon' piedra, a las cuales, obviamente, no se les ha aplicado la regla mencionada.

\section{Vocales epentéticas}

En saramaca, aparece también una serie de vocales epentéticas que no existían en el protopidgin original. Se trata de una regla que introduce una vocal idéntica a otra que constituye el núcleo de una sílaba formada por una consonante obstruyente y una consonante líquida / *1, *r /. Al parecer la vocal epentética aparece como compesación prosódica por la pérdida de las consonantes líquidas.

$\begin{array}{lllll}\text { saramaca } & \text { papiamento } & \text { palenquero } & & \\ \text { puúma } & \text { 'plúma } & \text { plúma } & \text { *plúma } & \text { pluma } \\ \text { duumí } & \text { 'drumí } & \text { drumí, } & \text { *drumi } & \text { dormir } \\ & & \text { ndrumí } & & \end{array}$




\begin{tabular}{|c|c|c|c|c|}
\hline gaándi & 'grándi & $\begin{array}{l}\text { ngánde, } \\
\text { glánde }\end{array}$ & *grándi & grande \\
\hline $\begin{array}{l}\text { feegá, } \\
\text { feigá }\end{array}$ & 'fregá & fregá & *fregá & fregar \\
\hline tiípa & 'trípa & $(-)$ & *trípa & intestinos \\
\hline
\end{tabular}

Esta regla se aplica también a los rubros de origen inglés y holandés.

$\begin{array}{ll}\text { diỉngi } & <\text { ing. drink 'beber' } \\ \text { goón } & <\text { ing. ground 'suelo' } \\ \text { baáka } & <\text { ing. black 'negro' } \\ \text { guúun } & <\text { hol. groen 'verde, azul claro' }\end{array}$

En 1779 esta regla no ocurría todavía en saramaca. Esto se nota en los siguentes ejemplos:

1779

'pluma'

'drummi'

'grandi'

'frigá, friká'

'grantripa'63

\section{forma actual}

puúma

duumí

gaándi

feegá, feigá

trípa

$$
\begin{aligned}
& \text { < port.pluma 'pluma' } \\
& \text { < port. dormir 'dormir' } \\
& \text { < port. grande 'grande' } \\
& \text { < port. fregar ' 'grande' } \\
& \text { < port. tripas 'tripas' }
\end{aligned}
$$

\section{Abreviaturas}

$\begin{array}{ll}\text { esp. } & \text { español } \\ \text { hol. } & \text { holandés } \\ \text { ing. } & \text { inglés } \\ \text { pal. } & \text { palenquero } \\ \text { pap. } & \text { papiamento } \\ \text { port. } & \text { portugués } \\ \text { sar. } & \text { saramaca }\end{array}$

\section{Notas}

1. El origen portugués de estos criollos ha sido ampliamente defendido. Para el caso del saramaca, véanse Perl et al. 1993 y Bickerton 1999. Para el caso del papiamento, véanse Granda 1974 y Maurer 1998a, quienes lo hacen provenir de una variedad importada directamente de África. Goodman 1987, Holm 1989 y McWhorter 1999, por su parte, sostienen que el papiamento proviene de una variedad de pidgin portugués que se utilizaría ya en las plantaciones de judíos sefarditas refugiados, provenientes del nordeste de Brasil a través de Surinam en 1659 y no directamente de África. Para el caso del palenquero, véanse Granda 1970, Megenney 1983, Perl 1989 a, 1990, Schwegler 1991, 1993, Moñino 2007.

2. El saramaca es considerado por algunos estudiosos un criollo de origen inglés relexificado con palabras portuguesas (cf. Goodman 1987, Ladhams 1999 a, 1999b y Parkvall 2000). Por su parte, tanto el origen como la filiación del papiamento son atribuidos por algunos al español (cf. Goodman 1987, Bakker et al. 1995, Arends 1999, Ladhams 1999a y 1999b, Parkvall 2000). Aunque no se discute la base española del palenquero, algunos sí dudan del origen portugués del pidgin que habría originado este criollo (cf. López Morales 1992; Lipski 1994, 1998). 
3. La fundación del palenque de los saramacas se remonta a 1690 con el escape masivo de esclavos de la plantación de Inmanuel Machado.

4. El papiamento fue llevado desde Curazao a Bonaire alrededor de 1700 y a Aruba a finales del siglo XVIII (Bartens 1995).

5. Las variedades de pidgis y criollos portugueses se extendían por África meridional (Angola), África oriental (Madagascar), el sudeste asiático (Birmania, Malasia, Indonesia), el subcontinente indio (incluida Sri Lanka), China y el Oriente Medio (Irán, Iraq y Arabia Saudita) (cf. Smith 1995). Los criollos españoles de las Filipinas tienen su origen también en un pidgin portugués (cf. Whinnom 1965).

6. La descripción de la fonología de esta lengua está basada en Taylor 1977, Voorhoeve 1959 y Rountree 1972.

7. La descripción de la fonología de esta lengua está basada en Kouwenberg \& Muysken 1995 y Maurer 1998 a.

8. Cf. Schwegler 1998 y Friedemann \& Patiño 1983.

9. Schwegler 1998 propone la fonologización de una serie de oclusivas sonoras tensas /·b, ·d, ·g/, las cuales, sin embargo, tendrían una distribución restringida a la posición intervocálica. Por esta razón, en este trabajo se prefiere considerar estos casos como instancias de geminación consonántica /bb, dd, gg/ bobbé volver, oddejá ordeñar, ággo algo.

10. Schwegler 1998 menciona también las prenaslizadas [กิt, $\widehat{\text { ns] }}$, ntré tres y nse se.

11. Riemer 1779 registra la forma barika.

12. Riemer 1779 registra la forma drummi.

13. En palenquero el significado de este rubro es decir disparates, hablar demasiado (Armin Schwegler, comunicación personal).

14. En saramaca esta palabra significa viejo.

15. Esta forma es arcaica en español (cf. Corominas 1983).

16. En papiamento, también existe la palabra 'poné, la cual es cognado de la forma palenquera. Estos rubros provienen presumiblemente del español.

17. El uso de los paréntesis indica que, en la respectiva lengua, la palabra correspondiente no es un cognado de las demás formas citadas.

18. En papiamento, también existe la palabra 'koré, la cual es cognado de la forma palenquera kolé. Ambos rubros provienen presumiblemente del español.

19. La reconstrucción de la forma saramaca está basada en Riemer 1779, quien recoge las formas 'mulêh' y 'moleh', cf. 2.3.b. infra. La forma actual usada en saramaca es dé de.

20. En palenquero también exite la forma morí, la cual proviene presumiblemnte del español. 
21. En saramaca, esta palabra significa universo.

22. El símbolo (-) indica que la palabra correspondiente no se encuentra en las fuentes.

23. Evidentemente, la palabra de saramaca es la reduplicación de la forma reconstruida.

24. Es muy probable que esta palabra provenga del español, ya que todos los demás numerales de 1 a 10 son claramente de origen español (cf. Maurer 1998b: 157).

25. En portugués, esta palabra significa solamente tío.

26. En portugués, esta palabra significa cautivo, prisionero. En 1779, en saramaca, el significado de este rubro era esclavo.

27. Este significado se deriva presumiblemente de la forma portuguesa bicho-da-seda 'gusano de seda'.

28. En portugués, esta palabra significa mundo. En 1779, en saramaca el signifcado de esta palabra también era mundo.

29. En portugués, esta palabra significa hierro. En 1779, en saramaca este término significaba hierro, acero.

30. En las lenguas de la península ibérica, este término proviene directamente del catalán relotge, actualmente rellotge. Sin embargo, en esta lengua, también se registra una forma más antigua arolotge (1368) que conserva la vocal / o / etimológica latina < horologium (Corominas, 1983). La derivación de esta palabra del portugués al papiamento sería la siguiente: relogio $\sim$ rologio relózio $\sim$ rolózio $>$ rolózio > olózii > olózi > oló $\int i$.

31. La derivación de esta palabra del español al papiamento sería la siguiente: ceniza se'nísa $\sim$ si'nísa >

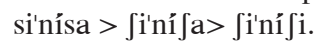

32. En papiamento, también existe la palabra 'búro, la cual es cognado de la forma palenquera.

33. La derivación de este rubro es la siguiente: negro *nígru > *nígri > níngri (1779) > *níngi > *nínge > nénge.

34. En papiamento, también existen la palabra 'négro, la cual es cognado de la forma palenquera, y 'négər, que proviene del holandés.

35. En 1779, el significado de este rubro era niño, al igual que en portugués.

36. En 1779, el significado de este rubro era permiso, al igual que en portugués.

37. Esta palabra aparece, por ejemplo, en los criollos ingleses de Nicaragua, San Andrés y Bahamas. También, se halla en otros criollos ingleses con las formas pikní o pikiní. En sranan y djuka, la forma este rubro es pikín, mientras que en saramaca el étimo relacionado es pikí pequeño.

38. Riemer 1779 recoge la forma 'dindra'.

39. Esta palabra es señalada por Taylor 1977 como arcaica. Riemer 1779 recoge la forma 'komè'. Otra posible interpretación fonológica para este término podría ser kumé, vid. infra. En ese caso, la protoforma 
reconstruida de este étimo sería entonces *kumé. Si esto fuera así, es probable que las formas 'kome del papiamento y komé del palenquero provengan del español y no del protopidgin afroportugués.

40. En saramaca, este rubro significa brillar.

41. La derivación del término actual del saramaca a partir de la protoforma recontruida es la siguiente:

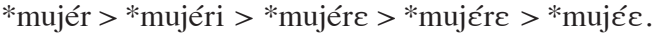

42. La derivación del término actual del saramaca a partir de la protoforma recontruida es la siguiente:

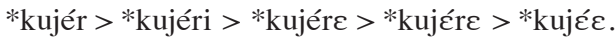

43. La derivación la forma actual del saramaca a partir de la proforma es la siguiente: *méstre $>$ * mésítre

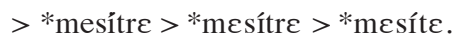

44. La derivación la forma actual del saramaca a partir de la proforma es la siguiente: *táempé $>$ *tánempé $>$ *tánampé > *tánampé > *tánapé.

45. Para la reconstrucción de las formas del protocriollo inglés del Atlántico, véanse Portilla 2001 y 2002.

46. Riemer 1779 recoge la forma 'contri' o 'kontri'.

47. En inglés, esta palabra significa solamente muerto.

48. La derivación de esta forma a partir del portugués maneira sería la siguiente: *manéra > *manéna > *manína > maníni.

49. Riemer 1779 recoge la forma 'ninga'.

50. Taylor 1977 reporta la forma véntu.

51. Naturalmente, la protoforma reconstruida está relacionada con el verbo portugués morrer.

52. Riemer 1779 recoge las formas 'floli', 'flolo' y 'froro'. La derivación la forma actual del saramaca a partir de la proforma es la siguiente: *flór > *flóro > flólo (1779) > folólo > foló.

53. La reconstrucción de rubros de un protocriollo inglés del Atlántico está basada en Portilla 2001 y 2002.

54. El significado de este marcador en saramaca es de aspecto durativo y en papiamento de tiempo presente.

55. Riemer 1779 recoge las formas 'kakkisa' y 'kassika'. La derivación de la forma actual a partir de la protoforma es la siguiente: *káska > kásíka (1779) > kákísa (1779) > ká kísa.

56. El significado de este rubro en saramaca es suegra, nuera y en papiamento es mami (forma de tratamiento).

57. El significado de este rubro en saramaca es suegro, yerno y en palenquero es compadre, amigo.

58. En papiamento, también existe la forma 'bakaláu, derivada presumiblemente del español. 
59. El rubro kakáo en saramaca proviene presumiblemente del holandés cacao y no del portugués ni del inglés.

60. En ciertos casos, cuando la consonante / s / va precedida de una vocal posterior, entonces la vocal epentética es / u / v. gr. lúsu (< ing. loose) soltar, músu (< ing. must) deber, lósu (< ing. louse) piojo.

61. Cuando la consonante / n / está precedida por una vocal anterior, suele aparecer una / i / como vocal epentética $v$. gr. péni (< ing. pen) lapicero, bolígrafo, wíni (< ing. win) ganar. Además, en estos y otros casos, la consonante / $\mathrm{n} /$ puede aparecer en posición final de sílaba; es decir, sin vocal epentética $v . g r$. wán (< ing. uno) one, pén (< ing. pain) dolor, mamáun (< port. mamaõ) papaya (vid.infra).

62. La derivación de esta forma a partir del holandés bloed sería la siguiente: *blu:d $>$ *bulúdu $>$ *bulúru *bulúlu > buúu.

63. El significado reportado por Riemer 1779 para este rubro es estómago.

\section{Bibliografía}

Amaro's papiamentu project. www.papiamentu.donamaro.nl.

Arends, Jacques et al. (eds.). 1995. Pidgins and Creoles. An introduction.

Arends, Jacques. 1999. "The origin of Portuguese element in Surinam Creoles". Huber \& Parkvall (eds.). Amsterdam/Filadelfia: Benjamins, 195-208

Bakker, Peter et al. 1995. "Saramaccan". Arends et al. (eds.),165- 78.

Bartens, Angela. 1995. Die iberoromanisch-basierten Kreolsprachen: Ansätze der linguistischen Beschreibung. Frankfurt/ Main: Peter Lang.

Bickerton, Derek. 1999. "An old argument revisted”. Bruyn et al. (eds.), 253-256.

Bruyn, Adrienne et al. (eds.). 1999. Mengelwerk voor Muysken. Amsterdam: Universiteit van Amsterdam.

Cásseres, Solmery. 2005. Diccionario de la lengua afro palenquera- español. Cartagena de Indias: Pluma del Monpox.

Cassidy, Frederic. 1971. "Tracing the pidgin element in Jamaican Creole”. Hymes (ed.), 203-221.

Clements, Clancy. 1992. "Foreigner talk ad the origins of pidgin Portuguese". Journal of Pidgin and Creole Languages. 7 (1): 75-92.

1999. "La monogénesis y la formación de algunos criollos de base portuguesa". Zimmermann (ed.), 277-93. 
2000. "Evidência para a existência de um pidgin português asiático". D’Andrade et al. (eds.), 185-200.

Corominas, Joan. 1983. Diccionario etimológico de la lengua castellana. Madrid: Gredos.

D’Andrade, Ernesto et al. (eds.). 2000. Crioulos de base portuguesa. Actas do Workshop sobre Crioulos de Base Lexical Portuguesa. Braga: Associacão portuguesa de linguística.

Díaz Alayón, Carmen (ed.). 1993. Homenaje a Pérez Vidal. Santa Cruz de Tenerife: Romero.

Friedemann, Nina S. de y Carlos Patiño. 1983. Lengua y sociedad en el palenque de San Basilio. Bogotá: Instituto Caro \& Cuervo.

Gadelii, Kart y Anne Zribi-Hertz (eds.). 2007. Grammaires créoles et grammaire comparative. Saint-Denis: Presses Universitaires de Vincennes.

Gilbert, Glenn (ed.). 1987. Pidgin and Creole languages: Essays in memory of John E. Reinecke. Honolulu: University of Hawaii Press.

Goodman, Morris. 1987. “The Portuguese element in American Creoles”. Gilbert (ed.), 361-405.

Granda, Germán de. 1970. “Un temprano testimonio sobre las hablas 'criollas' en África y América”. Thesaurus. 25 (1), 1-11

1974. "El repertorio lingüístico de los sefarditas de Curacao durante los siglos XVII y XVIII y el problema del origen del papiamento". Romance Philology. 28: 1-16.

Grimes, Joseph. (ed.). 1972. Languages of the Guianas. México: SIL.

Holm, John. 1989. Pidgins and creoles. Vol. 2. Cambridge: Cambridge University Press.

Huber, Magnus \& Mikael Parkvall (eds.). 1999. Spreading the word. Londres: Westminter University Press.

Huttar, George. 1972. “A comparative word list for Djuka”. Grimes (ed.), 12-21.

Hymes, Dell. (ed.). 1971. Pidginization and creolization of languages. Cambridge: Cambridge University Press.

Kouwenberg, Silvia y Pieter Muysken.1995. "Papiamento”. Arends et al. (eds.), 205-18.

Ladhams, John. 1999a. "The Pernanbuco connection? An examination of the nature and origin of the Portuguese elements in the Surinam Creoles". Huber \& Parkvall (eds.), 209-40. 
1999b. “Response to Norval Smith”. Huber \& Parkvall (eds.), 299-304.

Lipski, John.1994. "El lenguaje afroperuano: eslabón entre África y América”. Anuario de Lingüística Hispánica. 10: 79-216.

1998. “Perspectivas sobre el español bozal”. Perl \& Schwegler (eds.), 294-327.

2002. "Génesis y evolución de la cópula en los criollos afroibéricos". Moñino \& Schwegler (eds.), 65-101.

López Morales, Humberto. 1992. El español del Caribe. Madrid: Mapfre.

Maduro, Antoine. 1987. Palenkero i papiamentu. Korsou.

Maurer, Philippe. 1998a. "El papiamento de Curazao”. Perl \& Schwegler (eds.), 139-218.

1998b. Les modifications temporelles et modales du verbe dans le papiamento de Curaçao. Avec une antologie et un vocabulaire papiamento-français. Hamburgo: Helmut Buske.

McWhorter, John. 1999. “The afrogenesis hypothesis of plantation Creole origin”. Huber \& Parkvall (eds.), 111-52.

Megenney, William.1983. "La influencia del portugués en el palenquero colombiano". Thesaurus 28, 548-563.

1986. El palenquero. Un lenguaje post-criollo de Colombia. Bogotá: Instituto Caro y Cuervo.

Moñino, Yves. 2007. "Les rôles du substrat dans les créoles et les langues secrètes: le cas du palenquero, créole espagnol de Colombie”. Gadelii \& Zribi-Hertz (eds.), 49-72.

Moñino, Yves y Armin Schwegler (eds.). 2002. Palenque, Cartagena y Afro-Caribe. Historia y lengua. Tübingen: Niemeyer.

Naro, Anthony.1978. “A study of the origins of pidginization”. Language. 54 (2): 314-347.

Papiamento-English/ English-Papiamento lexicon. http:/www.ats-group.net/dictionaries/ dictionary-english-papiamento.html

Parkvall, Mikael. 2000. Out of Africa. African influences in Atlantic Creoles. Londres: Battlebridge Publications. 
Patiño, Carlos. 2002. "Sobre origen [sic] y composición del criollo palenquero". Moñino y Schwegler (eds.), 21- 49.

Perl, Matthias. 1989a. "Algunos resultados de la comparación de fenómenos morfosintácticos del habla bozal, de la linguagem dos musseques, del palenquero y de las lenguas criollas de base portuguesa". Estudios sobre el español de América y lingüística afroamericana. Bogotá: Instituto Caro y Cuervo, 369-380.

1989b. "Portuguiesch un crioulo in Afrika. Geschichte. Grammatik. Lexik. Sprachentwicklung”. Leipzig: Karl-Marx-Universität.

1990. "A reevaluation of the importance of early pidgin/creole Portuguese". Journal of Pidgin and Creole languages. 5: 125- 30.

Perl, Mathias y Armin Schwegler (eds.).1998. América negra. Panorámica actual de los estudios lingüísticos sobre variedades hispanas, portuguesas y criollas. Frankfurt/ Madrid: Vervuert/Iberoamericana.

Perl, Matthias et al. (eds.).1993. Portugiesich-basierte Kreolsprachen. Frankfurt: TFM.

Portilla, Mario. 1987. “Tipología de los sistemas vocálicos románicos”. Revista de Filología y Lingüística de la Universidad de Costa Rica. 13 (2): 109-118.

2001. "Reconstrucción del sistema fonológico del protocriollo inglés del Atlántico: Las vocales". Revista de Filología y Lingüística de la Universidad de Costa Rica. 27 (2): 199- 227.

2002. "Reconstrucción del sistema fonológico del protocriollo inglés del Atlántico: Las consonantes". Revista de Filología y Lingüística de la Universidad de Costa Rica. 28 (1): $165-87$.

2008. "Protopidgin afroportugués americano". Revista Internacional de Lingüística Iberoamericana (RILI). 6 (1): 161-83.

Riemer, Johann Andreas. 1779. Wörterbuch zur Erlernung der Saramakka-Neger-Sprache. www.sil.org/americas/suriname/Riemer/National/RiemerNLDict.

Rountree, S. 1972. “The phonological structure of stems in Saramaccan”. Grimes (ed.), 22-27.

Saramaccan - English Dictionary. www.sil.org/americas/suriname/Saramaccan/English/ SaramEngDictIndex. 
Smith, Norval. 1995. "An annotated list of creoles, pidgins, and mixed languages". Arends et al. (eds.), 331-374.

Stolz, Thomas. 1987. “Verbale morphosyntax derportugiesisch-basierten Kreols”.Iberoamericana. 11: 35- 59.

Schwegler, Armin. 1991. "Zur Problematik der afroportugiesischen Kontaksprache in Amerika: Nenes aus El Palenque de San Basilio (Kolumbien)”. Lusorama. 15: 54-79.

1993. "Rasgos (afro-) portugueses en el criollo de Palenque de San Basilio (Colombia)". Díaz Alayón (ed.), 667-696.

1998. "El palenquero”. Perl y Schwegler (eds.), 218-91.

Taylor, Douglas. 1977. Languages of the West Indies. Baltimore/Londres: The Johns Hopkins University Press.

Voorhoeve, Jan. 1959. “An orthography for Saramacca.”. Word. 15: 436-45.

Whinnom, Keith. 1965. "Origin of European-based creoles and pidgins”. Orbis. 14 (2): 509-27.

Zimmermann, Klaus (ed.). 1999. Las lenguas criollas de base lexical española y portuguesa. Frankfurt/Madrid: Vervuert/Iberoamericana. 